\title{
La boda de penalty: el romance de Los primos romeros o la resolución poética de un conflicto vulgar
}

\author{
"-Querida Eugénie, un primo es mejor que un \\ hermano; puede casarse contigo - le dijo Charles." \\ HONORÉ DE BALZAC, Eugénie Grandet
}

El pueblo cantor de romances no cree en la teoría del arte por el arte. Cada romance es poético, sí, pero cada romance es también, y sobre todo, útil. Las historias que cuentan los romances son historias ejemplares. Esto no quiere decir que el romancero caiga en ningún tipo de didactismo al estilo de los fabulistas del siglo xviII o de la novela estalinista de tiempos más recientes, sino simplemente que, recogiendo la tradición clásica —y también medieval—, intenta enseñar al mismo tiempo que entretener. El romance es poesía, pero esta poesía siempre nos remite invariablemente a una verdad de la vida y así esa forma poética resulta socialmente funcional.

Diacrónicamente, estas funciones del romance pueden variar sensiblemente. Tal vez sea cierto que los primeros romances desempeñaron predominantemente una función noticiera, pero hoy, lo más frecuente es que, lejos de la actualidad o de la historia con mayúsculas, se centren en los problemas de la intrahistoria del pueblo, en los conflictos familiares y anónimos de la vida cotidiana. Este último caso es el del tema romancístico del que enseguida nos vamos a ocupar. Pero, antes de meternos en harina, conviene hacer alguna otra precisión previa.

Ninguna versión - performance - de un romance agota el sentido o las posibilidades de sentido que pudiera contener la intriga. Pudiera decirse que cada vez que alguien canta un romance, en realidad lo que está haciendo es ofrecernos su versión de unos hechos ocurridos idealmente en el pasado. Y, por lo tanto, el cantor omite unos aspectos y subraya otros. Cada versión es un balance de olvidos y recuerdos, bien sean intencionados o casuales, conscientes o inconscientes, frutos de la mala memoria, del error de interpretación, o de la preferencia y la elección. Lo que ocurre es que cada cantor saca sus propias consecuencias de la fábula que relata: parecidas a las de otros, o muy parecidas, pero rara vez idénticas. Estas variaciones - toda tradición vive a través de varian- 
tes- pueden ser menores y secundarias o bien pueden revelarse como importantes y de fondo. Aunque todas remiten a un único texto ideal que, sin embargo, nadie nunca podrá tener entre sus manos o registrarlo en cinta magnetofónica. Ese texto ideal existe y no existe al mismo tiempo. Como la esencia de las cosas, sólo se revela a través de efímeras, problemáticas y cambiantes apariencias.

En realidad, el cantor es un lector: lo que nos está ofreciendo es su lectura de ese texto ideal, su relectura del romance.

Normalmente, el lector es silencioso y anónimo. No deja huella. De los millones de lectores - pasados, presentes y futuros- del Quijote de Cervantes o de Die Wablverwandtschaften de Goethe lo ignoramos $-\mathrm{y}$ lo ignoraremos - todo. De hecho, sabemos que existen, porque estos libros no cesan de reeditarse. Pero lo que los simples lectores -si es que a algún lector se le puede llamar simple - entienden de estas novelas, las enseñanzas que sacan, los sentimientos que les inspiran... eso pertenece al misterio más arcano. Sólo unos pocos lectores privilegiados y minoritarios - lo que no quiere decir que no puedan ser simples- exponen por escrito sus impresiones. Es el caso, por ejemplo, de los críticos literarios, los profesores de universidad o los escritores que hablan de obras de otros escritores.

En el caso del romancero, los lectores se imponen sobre la obra ${ }^{1}$. De hecho, la obra no existe más que si existen lectores, o sea, cantores. El cantor es un intérprete, es decir, un lector. Su lectura se realiza a través del canto de acuerdo con la versión que guarda en su memoria. El lector-cantor, lo que los encuestadores de literatura oral llamamos "el infor-

1 Ya Ramón MENÉndeZ PIDAL, en su Romancero Hispánico (Madrid: Espasa Calpe, 1968), t. I, pp. 9-10, había hecho notar lo siguiente: "Todo el que disfruta de una obra de arte le añade algo de su propia sensibilidad, colaborando con el artista; pero tratándose de obras consumadas perfectamente, esa colaboración queda inexpresada, o se expresa aparte en un juicio crítico, o a todo más se incorpora a la obra con los matices acústicos de una recitación en público, mientras que tratándose de una obra tradicional, recibida como herencia propia, la colaboración del que la disfruta se hace más expresa y activa en las fugaces variantes que se introducen en la obra misma" Recoge esta idea Paloma DíAZ-MAs, Romancero (Barcelona: Crítica, 1994, col. "Biblioteca Clásica" núm. 8), pp. 15-16: "en el mismo acto de la oralidad, el individuo es al mismo tiempo lector, transmisor e intérprete del texto, proyectando sobre él -la mayor parte de las veces inconscientemente, aunque no falten intervenciones conscientessu propia lectura", aunque, a nuestro juicio, ampliándola en exceso: "Un mismo romance, cantado por dos personas distintas, puede ser entendido de dos maneras distintas, y en una próxima recitación esa diferencia de entendimiento puede plasmarse en una modificación, tal vez mínima, pero que ponga en marcha una posible vía de relectura del romance por otros transmisores*. 
mante", ha memorizado una versión de la obra. Adapta, o bien recibe en herencia una adaptación ya concluida, y la repite una y otra vez.

Por supuesto, aquí también el crítico, académico o no, sigue siendo un lector privilegiado. Al contrario que los simples informantes, que sólo conocen la versión que se canta en su pueblo o en su familia, el crítico viaja y lee. Viaja mucho y lee -leer es otra forma de viajar- aún más. Por tanto, está en condiciones de confrontar múltiples, casi innúmeras versiones. En el campo de la literatura oral, el crítico disfruta incluso de mayores privilegios que el crítico del Quijote o de Madame Bovary. En su caso, conoce, o puede conocer, las lecturas de centenares de miles de individuos, el despliegue de los sentidos del texto a través del tiempo y del espacio, de la historia y de la geografía.

Pues bien, ya que disponemos de este privilegio, vamos a utilizarlo a propósito de un romance que aún resulta muy popular en España y particularmente en Andalucía. Se trata del romance de Los primos romeros (según el título codificado por el CGR, que le asigna el número 0142) a veces llamado también "Los peregrinos" o "La peregrinita" ${ }^{2}$.

Como no existe un texto único, definitivo, autorizado por su autor, sino sólo huellas, rastros, pistas, vamos a escoger aquellos restos que nos parecen más completos, que mejor idea nos dan de cómo podía ser el esqueleto de este fósil ideal, o, mejor dicho, de este fósil aparente. Partamos pues de una versión "lo más completa posible", sin que ello quiera decir la más extensa. Bien pudiera ser alguna como esta, recogida en Riaza, provincia de Segovia, en 1905, por María Goyri y Ramón Menéndez Pidal:

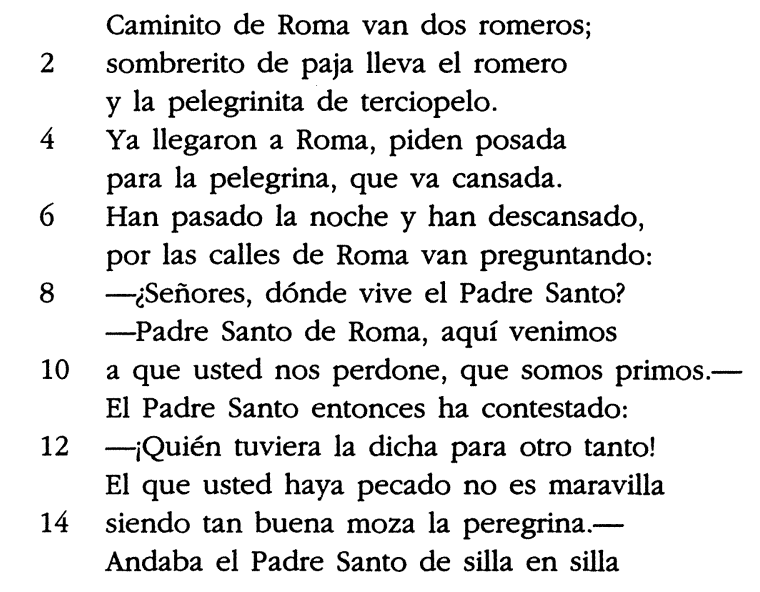

2 El Romancero pan-bispánico. Catálogo general descriptivo, ed. de Diego CATALÁN y otros (Madrid: Seminario Menéndez Pidal, 1982-84), 3 vols. 
16 para verle la cara a la peregrina. -Pelegrinita linda, de buen parece[r]

18 dame tus ojos negros, te perdonaré.

-Estos mis ojos negros no son para vos,

20 si usted no nos perdona, nos perdona Dios.

-Pelegrinita linda, vámonos de aquí,

22 que me está pareciendo que me voy $\sin$ ti $^{3}$.

¿Qué extraño romance! (Aparte de que, por su forma métrica, no se trata de ningún romance, aspecto este ya notado y resuelto por Mercedes Díaz Roig) ${ }^{4}$. En principio, dudamos de si se trata de un texto anticlerical, al presentarnos a ese Papa inflamado de lujuria ante la contemplación de la bella peregrina - y no un clérigo cualquiera, como es frecuente ver en los cuentos y refranes populares, sino ¡nada menos que el Papa!-, o si, por el contrario, estamos ante un texto surrealista avant la lettre, con ese $\mathrm{Pa}$ dre Santo que salta, como un mono, "de silla en silla" o, en otras versiones más surrealistas aún, "de cubo en cubo". En todo caso, la escena presenta visos esperpénticos, de caricatura bufa. Pero no debe todo esto resultar tan extraño para los cantores anónimos, que lo siguen cantando en nuestros días como si tal cosa, es decir, como si para ellos tuviera un sentido.

Pues bien, sí: nada de anticlericalismo, nada de surrealismo. Para los cantores anónimos todo es mucho más simple, porque el romance que cantan hace alusión a un conflicto corriente en la sociedad y en las familias. Es una historia ejemplar que refiere en tono poético un hecho vulgar, trágico o cómico, o tragicómico, según sea el enfoque que le queramos dar o, mejor dicho, que le podamos dar, según sea nuestra perspectiva. En todo caso, el romance refleja una gran sabiduría. Una sabiduría popular. Y, después de todo, ¿no es esto lo propio de los textos folclóricos?

Nada de anticlericalismo, nada de surrealismo. Pero tampoco nada de incesto. Conviene decirlo porque algunos estudiosos han leído el romance desde esta clave ${ }^{5}$.

3 Tomo el texto del Romancero General de Segovia. Antología [1880]-1992, preparado por Raquel Calvo bajo la supervisión de Diego CATALÁn (Segovia: Diputación Provincial, 1993), p. 495.

4 Cfr. Mercedes DíAz RoIG, El romancero y la lírica popular moderna (México: El Colegio de México, 1976), pp. 227-231.

5 Así, por ejemplo, María del Carmen GARCía SURRAllés, Estudio del romancero de Cádiz (zona atlántica) (Tesis doctoral inédita leída en la Universidad de Sevilla, 1988), p. 664: "Su tema está relacionado con el incesto entre parientes colaterales en cierto grado. Al estar aceptado social y moralmente siempre que haya dispensa, no da lugar al tratamiento trágico con que se presentan en literatura otros tipos de incesto". Tam- 
Para empezar, el incesto en las sociedades occidentales tiene lugar entre padres e hijos o hermanos entre sí, nunca entre primos. En el vigente código penal español (1995) el delito de incesto ni siquiera existe como tal, y tan solo cuando algún delito contra la libertad sexual se ejerce sobre familiares, por consanguinidad o por adopción, se agrava la pena. En cuanto a la legislación civil española, el matrimonio entre primos hermanos ni siquiera necesita dispensa del juez, ya que es una relación colateral de cuarto grado, siendo así que la ley exige esta dispensa sólo para el tercer grado (tío y sobrina, por ejemplo). Es verdad que en la legislación canónica fue precisa la dispensa papal (ahora, sólo la del ordinario de la diócesis), pero no porque el matrimonio entre primos constituya incesto, sino precisamente porque no lo es (en la terminología canónica, se trata sólo de un "impedimento dirimente"). Como es lógico, la Iglesia no puede conceder permiso para pecar. Y el incesto es un grave pecado que, naturalmente, la Iglesia condena en cualquier caso y sin excepciones. Para la Iglesia, el incesto no puede recibir dispensa inunca!

Además de la legislación civil, penal y canónica, está el hecho de que el romancero cuenta ya con suficientes romances de incesto, que agotan la casuística: Tamar (incesto entre hermanos), Delgadina (padre e hija), Silvana (también entre padre e hija, pero aquí frustrado por la ingeniosa intervención de la madre). ¿Para qué introducir (y no olvidemos que el de la peregrinita es una narración tradicionalizada bastante tardía, es decir, muy moderna, sólo encontrada a partir del s. $\mathrm{xx})^{6}$ otro más? Por otro lado, cuando el incesto aparece en el romancero, siempre va acompañado de la violación o la fuerza, y siempre resulta, pues, afeado y condenado. Por supuesto, jamás es absuelto ni tan siquiera comprendido o tolerado ${ }^{7}$.

bién lo incluye entre los romances de incesto Jon TALOS, Enzyklopädie des Märchens. Handwörterbuch zur bistorischen und vergleichenden Erzäblforschung (Berlin: Walter de Gruyter, 1991), pp. 229-241 (entrada: Inzest).

6 La primera vez que se documenta este tema de Los primos... es en las colecciones de Ledesma (Salamanca, 1907). En los años treinta lo recogerían también Schindler y Bonifacio Gil. El hecho de que García Lorca armonizase una versión en sus "Canciones populares españolas", que grabó con la Argentinita, le proporcionó una difusión extraordinaria, aunque a otro nivel. Los discos se pusieron a la venta en el año 1931. Hay edición moderna —en CD- en Madrid, Sonifolk, 1994. Una reciente y conseguida versión aflamencada de estas canciones es la de Carmen Linares, "Canciones populares antiguas recopiladas por Federico García Lorca", París, Auvidis, 1994.

7 Cfr. Manuel GuTiÉRrez EstÉvEz, "Sobre el sentido de cuatro romances de incesto", Homenaje a Julio Caro Baroja, Madrid, 1978, pp. 551-579, que no incluye Los primos romeros, pero considera que Blancaflor y Filomena es también un romance de incesto, por el hecho de que el cuñado fuerce a la cuñada. A nuestro juicio, el adul- 
Así, pues, no se trata de incesto pero, entonces, ¿de qué trata el romance de los peregrinos?

Prescindamos por un momento del hecho de que estos dos jóvenes sean primos. El propio romance lo considera algo secundario, ya que en algunas versiones se nos presentan como "Los que fueron amantes/y ahora son primos" 8 . Primos reales, o primos sobrevenidos, lo cierto es que son dos jóvenes que se dirigen a Roma, centro moral del orbe católico, el centro más central de todos, la autoridad por antonomasia, a pedir permiso, respaldo y confirmación para su unión carnal y legal. Pero en ese camino ocurre lo imprevisto o, mejor dicho, lo no deseable. Ocurre un accidente:

$$
\begin{aligned}
& \text { Al pasar el arroyo de la Victoria, } \\
& \text { tropezó la madrina, cayó la novia. } \\
& \text { El padrino se ríe y el novio llora } \\
& \text { al ver que se ha caído la pobre novia. }
\end{aligned}
$$

(Versión de Arcos de la Frontera, Cádiz, de José María Capote y Josefa Benot, recogida en 1983 por Virtudes Atero y Pedro M. Piñero, Archivo de la Fundación Machado: en adelante AFM)

Por supuesto, esta caída no puede ni debe entenderse en sentido lite$\mathrm{ral}^{9}$. Ningún detalle puede ser ocioso, superfluo o anodino en un poema, sea este de la clase que sea, culto o popular. El noviazgo, al menos en los países cristianos, se ha concebido siempre como la etapa preparatoria de los que pretenden contraer matrimonio, de la cual queda excluida y prohibida la relación carnal. La virginidad de la novia (otra cosa sería la del novio) debe preservarse a toda costa, para que íntegra llegue al matrimonio. Lo malo es que sabemos que eso no siempre ocurría ni ocurre. El ardiente temperamento de los jóvenes rompía no pocas veces leyes tan estrictas. Y se producían "caídas", como esta tan aparatosa que sufre nuestra novia-peregrina. Hay versiones de este romance en que la alusión no sólo a la pérdida de la virginidad, sino al embarazo de la joven son tan poéticas como explícitas:

terio, la violación y el asesinato ya serían temas suficientes para el romance, sin necesidad de añadir el incesto (aquí, además, no pertinente).

8 Cfr. Fernando FloRes MANZANO, Una cala en la tradición oral extremeña: Estado actual del Romancero en el Valle del Jerte (Mérida: Asamblea Regional de Extremadura, 1994).

9 Así parece haberlo entendido Jon TALOS para incluirlo entre los romances de tema incestuoso: "Vetter und Base heiraten manchmal mit Dispens des Papstes, aber auch dann bleibt ihnen eine Katastrophe nicht erspart: Das Brautpaar ertrinkt im Fluss." (art. cit., p. 236) 


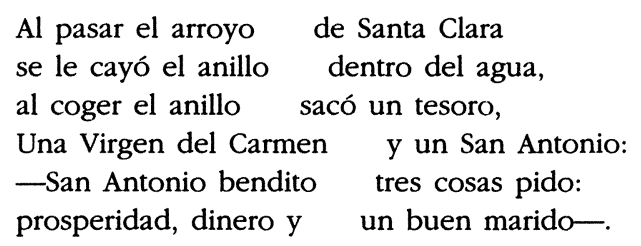

(Versión de Barbate, Cádiz, de Oliva Muñoz Soler, de 80 años, recogida en 1985 por Soledad Bonet, AFM)

Nos imaginamos, en el tropiezo de la madrina, a la figura típica de la "carabina" que acompañaba y vigilaba a los novios de tantos pueblos, cuya misión era precisamente prevenir y evitar estos terrenos tan resbaladizos. Aquí, por lo que se ve, el centinela se quedó dormido. El padrino ríe: por supuesto, en estos casos, siempre hay quien se alegra, quien murmura, quien cotillea, quien abiertamente se ríe de la desgracia de los demás. $\mathrm{O}$, simplemente, quien comprende que, después de todo, tampoco es tan trágico.

Pues bien, ya tenemos planteado el caso. Un caso perfectamente vulgar, pero que ha provocado conflictos en muchas familias. El padre de la novia puede montar en cólera y expulsar a la hija de la casa. El novio puede tener pretensiones serias, pero a veces es sólo un seductor que, una vez desgraciada la flor, vuela a picotear en otro sitio y deja a la pobre muchacha en la situación -indeseable para la sociedad tradicional- de madre soltera, de mujer seducida y abandonada. Cuántas novelas no se han escrito sobre este conflicto familiar. También, por descontado, el romancero nos ofrece una nutrida ración de seducidas, de madres solteras, de hijos del pecado, de galanes que huyen después de haber gozado a la dama. Sin necesidad de echar mano ahora al repertorio de los ciegos, recordemos tan sólo los romances de La mala bierba, La apuesta ganada, Galiarda, La infanta burlada o el firme pronunciamiento que hace Gerineldo en algunas de sus versiones más crudas:

$$
\begin{aligned}
& \text { Una promesa le debo a la Virgen de la Estrella: } \\
& \text { mujer que duerma conmigo no me he de casar con ella. }
\end{aligned}
$$

¡Y eso que se le está proponiendo casarse nada menos que con la hija del rey!

Afortunadamente, el peregrino de nuestro romance no es de esos: "...y el novio llora/ al ver que se ha caído la pobre novia". No, el peregrino no es un donjuán ni un caradura. Es un muchacho algo ingenuo, verdaderamente enamorado de su novia, que quiere reparar el daño causado, no sólo por motivos éticos o compasivos, sino porque, como decimos, ama y estima a la caída peregrina, a la que quiere por esposa. 
Pero no se crea que las cosas son tan fáciles. No basta con declararse dispuesto al matrimonio. El escándalo ya se ha producido ("tropezó la madrina"... "el padrino se ríe"...). La sociedad tradicional no es tan indulgente como la de nuestros días. Hay, pues, que sufrir una prueba, un examen del que posteriormente se derive la plena sanción del matrimonio.

Así, pues, concurren ante la alta autoridad del Santo Padre. Al igual que la caída de la novia al pasar el arroyo, tampoco la figura del Papa debe tomarse en sentido literal. El personaje cuya encarnadura es aquí el Papa no es sino la representación del Juez, del Padre, del Poder, del SuperYo, o como quiera que queramos llamarle. En definitiva, de la sociedad y de sus normas, usos y ritos. Comienza el Papa por someter a los peregrinos a un somero interrogatorio que va a servir como truco narrativo para ir presentándonos mejor a los novios, caracterizándolos de manera más concreta y visual, con los datos mínimos para conocer tanto a una persona como a un personaje: el lugar y la fecha de nacimiento.

Ella dice: de Francia Él: de Inglaterra.

y ella dice de Ubrique y él de Alhucema.

ella dice de Cabra y él de Antequera.

Lo que no varía en casi ninguna versión, como no podía ser de otra manera, es la edad, tan joven, de los peregrinos.

ella dice que quince y él diecinueve.

Después de estos preámbulos (que a veces incluyen asimismo el nombre de pila de los jóvenes), llega la pregunta crucial.

$$
\text { le ha preguntado el Papa que si han pecado. }
$$

$\mathrm{Y}$ el peregrino, que no es nada taimado y lleva buenas intenciones, responde con sinceridad: "Al pasar del arroyo le di la mano". Púdica expresión tanto de la entrega carnal como matrimonio de facto, como de la promesa de posterior matrimonio de iure (¿no existe la expresión coloquial "pedir la mano"?). En otros casos, es ella quien reconoce su ignorancia de las normas sociales: "Le ha preguntado el Papa por la doctrina./ Dice que no la sabe, la $m u$ cochina." (Versión de Utrera, Sevilla, de María Peña Vargas, recogida en 1986 por A. J. Pérez Castellano y Enrique Baltanás, AFM).

Pero ahora ocurre lo imprevisible. En vez de comportarse como justo juez, y con la prudencia y seriedad que cabría esperar de quien ostenta 
tan alta autoridad, el Papa de nuestro romance comienza a mostrar tan inquietantes como evidentes síntomas de hallarse poseído por la lujuria más desvergonzada. Los cantores más pacatos prefieren relatar que el Papa, o bien se muestra envidioso del peregrino que disfruta de tan guapa moza, o bien disculpa y comprende la actuación del mancebo ya que él mismo, de no mediar sus votos de castidad, hubiera hecho otro tanto en parecidas circunstancias.

$$
\begin{aligned}
& \text { Responde el Padre Santo con mucho llanto: } \\
& \text { iQuién tuviera licencia para otro tanto! } \\
& \text { (Versión de Riaza, Segovia, cit.) }
\end{aligned}
$$

Pero también hay cantores que tienden a subrayar y a exagerar este extraño comportamiento del Papa y cargan las tintas en lo tocante a la lubricidad del pontífice, que pasa de lo reflexivo a lo pragmático:

$$
\begin{aligned}
& \text { Andaba el Padre Santo, y en cubo en cubo, } \\
& p a \text { cogerle la mano con disimulo. } \\
& \text { Andaba el Padre Santo, en villa en villa, } \\
& p a \text { cogerle la mano a la pelegrina. }
\end{aligned}
$$

(Versión de Arcos de la Frontera, Cádiz, de Remedios Perdigones, Josefa Oliva, Josefa García y Amelia Sena, recogida en 1982 por Virtudes Atero y Pedro M. Piñero, Romancerillo de Arcos, Cádiz, Diputación Provincial y Fundación Machado, 1986, p. 101).

La lujuria del clérigo es motivo frecuente de la cuentística popular y muy abundante en el refranero: "A casa del cura ni por lumbre vas segura" ${ }^{10}$. La cuestión se encuentra asimismo en el romancero moderno, perfectamente representada en el picaresco romance de El cura enfermo:

$$
\begin{aligned}
& \text { Estaba un curita malito en cama } \\
& \text { y a la media noche llama a la criada. }
\end{aligned}
$$

Sin embargo, no es este el caso del romance que ahora consideramos. La lujuria del Papa de nuestro romance no aparece con intención anticlerical o simplemente humorística, sino como reforzadora de la disculpa de la conducta de los jóvenes. ¿No iban a pecar si hasta el propio Papa confiesa que hubiera hecho otro tanto e incluso, más todavía, quiere robarle la novia al pobre peregrino? Explícitamente se dice en una de las versiones orales: "Peregrinita hermosa, vamonos p'allá/ que el Papa es

10 Cfr. Manuel Bernal Rodríguez, El hábito no hace al monje. Clero y pueblo en los refraneros españoles del Siglo de Oro (Sevilla: Padilla Libros, 1994). 
hombre/ como los demás" ${ }^{11}$. Mucha es la fuerza de la belleza de una mujer, muy intenso su atractivo, que se ejerce sobre cualquiera, cuanto más sobre un joven en la plenitud de su mocedad. Seamos, pues, comprensivos con el pecado de estos jóvenes - parece querer decirnos el romance-, en razón, como afirmaba un buen conocedor de los romances, y del pueblo que los canta, Lope de Vega, de "que los yerros por amor/ fácil son de perdonar".

Sin duda, lo que la voz anónima que resuena en este romance quiere proclamar aquí es la inocencia de los jóvenes, a pesar de su desliz, y lo que quiere reivindicar es su perdón, su reinserción o vuelta al orden social, es decir, su derecho a la felicidad a través de la consagración de su amor en el matrimonio. En unas versiones, es la lubricidad del Papa la que sirve de justificación, como hemos visto. Pero incluso cuando esto no ocurre, y el Papa se muestra como autoridad inflexible, es la propia voz popular la que interviene en favor de los jóvenes.

$$
\begin{aligned}
& \text {-Por penitencia pongo que no se vean } \\
& \text { de noche ni de día semana y media. } \\
& \text { - ¿Padre Santo de Roma, cómo consiente } \\
& \text { que dos enamorados vivan ausentes? }
\end{aligned}
$$

(Versión de María Santos Valencia, de 43 años, recogida en Algeciras, Cádiz, por Francisco Vegara y Carmen Tizón en 1985, AFM)

En la escena de la audiencia papal, lo que el romance viene a concluir, muy evangélicamente, es que "no juzguéis y no seréis juzgados", que "el que esté libre de pecado que arroje la primera piedra", que tan humano y tan del mismo barro es el juez como el juzgado, y de ahí que cuando el Papa se lamenta:

$$
\begin{aligned}
& \text { ¡Quién tuviera la dicha } \\
& \text { para otro tanto! } \\
& \text { Contesta el pelegrino, } \\
& \text { con gran solapa: } \\
& \text { - Sea usté pelegrino } \\
& \text { yo seré el Papa }{ }^{12} \text {. }
\end{aligned}
$$

La escena de la audiencia papal ha cumplido su doble misión en la cadena narrativa del romance. Por un lado, subraya la hermosura cautivadora e irresistible de la peregrina (una escena semejante a la del romance de La Bella en misa: "el que está en el campanario/ de cabeza se cayó...

11 Fernando Flores MANZANO, op. cit., p. 204.

12 Ibid., p. 205. 
el que cerraba las puertas/ cuatro dedos se pilló... Y el que decía la misa/ por decir "Dominus ubiscó/ Mal haya sea el amor...") ${ }^{13}$. Por otro, justifica la conducta del mancebo a través de la del Papa. Y, una vez cumplida esta doble función, poco importa si los peregrinos obtienen el explícito perdón del Papa, o si salen corriendo.

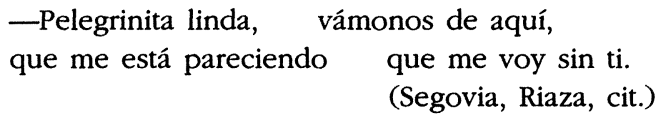

Ya se ha mostrado lo que se quería. De hecho, un gran número de versiones concluyen aquí. Otros cantores alargan la historia, bien sucintamente:

$$
\begin{aligned}
& \text { Las campanas de Roma ya repicaron } \\
& \text { y los peregrinitos ya se han casado. }
\end{aligned}
$$

O bien de modo más prolijo y circunstanciado:

$$
\begin{aligned}
& \text { A la entrá de Valencia tuvo una niña, } \\
& \text { por el nombre le ponen Rosa María. } \\
& \text {-Estarás contentillo, primo del alma, } \\
& \text { las dos peregrinillas de tus entrañas. } \\
& \text { - Por gozar tu hermosura mira cómo ando, } \\
& \text { por las calles de Roma peregrinando. } \\
& \text { Que si este es el renglón, y este es el renglón, } \\
& \text { que si tú eres mi vida, yo soy tu amor. }
\end{aligned}
$$

(Versión de Sigueruelo, Segovia, de Gabriela Moreno, de 54 años, recogida en 1947 por Diego Catalán en Romancero general de Segovia, cit.)

El núcleo del relato se rodea casi siempre de elementos secundarios, de desigual importancia. Muy escasa es la que posee la indumentaria de los romeros -"Sombrerito de hule lleva el mozuelo/ y la peregrinita de terciopelo"-, que tiende a realzar el decoro de los personajes, o que la niña les nazca en la misma Roma o ya de vuelta a casa; que la peregrinita pida posada - como la Virgen preñada camino de Belén- o que la niña hable para concluir el relato. Todo esto no es más que, en palabras de Mercedes Díaz Roig, "el bordado alrededor de la historia".

En cambio, sin dejar de ser bordado, reviste mayor alcance en el tejido de la historia el hecho de que los jóvenes sean primos o que vayan

13 Cfr. Pedro M. PIN̂ERO y V. ATERO, "La bella en misa gaditana: un revuelo erótico-festivo en el templo", Estudios de Folklore y Literatura dedicados a Mercedes Díaz Roig (México: El Colegio de México, 1992), pp. 315-324. 
de romería. En la lírica popular, sobre todo en la copla flamenca, encontramos la palabra prima (o primo) como equivalente a amante o amiga. $\mathrm{Y}$ es frecuente que los gitanos se llamen 'primos' entre ellos, aunque no se toquen nada. Sobre los riesgos y tentaciones a que se exponen los primos hay abundantes testimonios del refranero: "Si tienes novia con primos, tú harás el primo"; "Con achaque de primo, a la primita me arrimo"; "Con achaque de primo, entro y te veo"; "Cuanto más primo, más me arrimo"; "Dicen y decimos que es peligroso el trato entre primas y primos"... ${ }^{14}$ En la lírica popular, el matrimonio entre primos no es en absoluto desconocido:

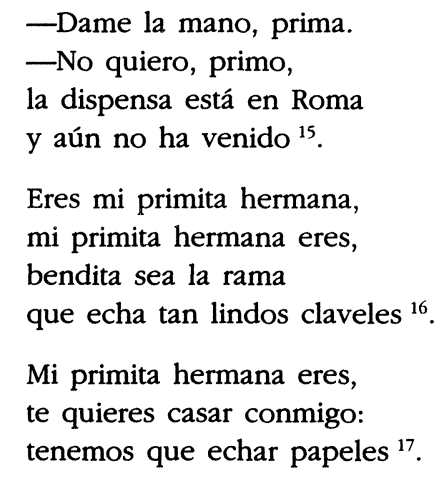

Pero aquí el hecho de que los personajes sean primos está sólo en función de que se vean en la necesidad de peregrinar a Roma, ante el Santo Padre (y tal vez como aviso de los riesgos que la cercanía física y el trato frecuente entre los jóvenes puede comportar). Al Papa, en el romancero y en la lírica popular, se atribuyen poderes extraordinarios. Rodríguez Marín recogía ya la siguiente copla:

14 Cfr. Luis MARTÍNEZ KLEISER, Refranero general ideológico español (Madrid: Hernando, 1899).

15 Apud Alberto SEvilla, Cancionero popular murciano (Murcia: Imprenta Nogués, 1921), p. 44.

16 Apud Eduardo Tejera RoBles, Literatura de tradición oral en Ávila (Ávila: Diputación Provincial, 1994), p. 150.

17 Copla cantada por El Borrico de Jerez en una grabación editada por Hispavox, en 1980, realizada y dirigida por José BlAS VeGA, y que sin duda no es sino una variante de la que recogió Demófilo en su Colección... de 1881: "¿Tienes baló e quererme/ sabiendo que somos primos,/ Tenemos de pagá er brebe?". Ver Antonio MACHADO y ÁlVAREZ, Colección de cantes flamencos, edición, introducción y notas de E. BaltanÁs (Sevilla: Portada Editorial, 1996), p. 146, n. 315. 
Te den una puñalá, que er Padre Santo de Roma no te la puea curá ${ }^{18}$.

En el romancero, es también el Papa el único que puede absolver pecados extremos, como la violación incestuosa de Tamar por su hermano Amnón:

No te dé pena, hija mía, que en Roma dispensa el Papa,
te casarás con tu hermano y serás reina de España ${ }^{19}$.

Como ya hemos visto, se requiere la autoridad del Papa para sancionar el nuevo matrimonio de estos impulsivos jóvenes que han forzado su etapa prematrimonial.

Aunque la romería es un motivo frecuente en la literatura, tanto culta como popular, aquí aparece en función de vía purgativa simbólica para la vuelta al orden: se sale del lugar habitual y cotidiano, cuyas reglas se han violado, para volver al mismo lugar habitual y cotidiano, reconciliados y perdonados.

Las relaciones sexuales prematrimoniales han sido abundantemente reflejadas en la literatura. Dentro del campo del romancero, podríamos decir que Los primos romeros, más que con romances de incesto, con quien más parentesco guarda es con el conocidísimo de Gerineldo $^{20}$, con la diferencia de que en éste el matrimonio lo impone el padre de la muchacha ("Mientes, mientes, Gerineldo,/ con la princesa has dormido,/ supuesto que la has gozado,/ has de ser tú su marido."), mientras que en Los primos romeros son los propios jóvenes los que procuran el himeneo. Generalmente, el tema aparece en tono condenatorio y con tintes trágicos. Lo más normal, viene a decirnos esta literatura, es que la novia que tan fácilmente se entrega, que tan poco defiende la integridad de su virginidad, sea abandonada y tenga que cargar con el fruto de sus ilícitos amores. Todas estas relaciones dentro del campo mismo de la literatura no

18 Apud. F. RODRíguez MARín, El alma de Andalucía en sus mejores coplas amorosas (Madrid, 1929).

19 Cfr. José María DE Cossío, Romancero popular de la Montaña (Santander, 1933-34).

20 Cfr. Michelle DÉBAX, "Histoire(s) de famille dans le romancero traditionnel. Les amours de l'infante et du page dans le romance de Gerineldo", Le texte familial (Textes hispaniques) (Toulouse: Université de Toulouse-Le Mirail, 1984), pp. 35-58. Ver también E. BalTANÁs, "Una heroína anónima del Romancero: la princesa de Gerineldo", Revista de Folklore, núm. 187 (1996), pp. 14-20. 
deberían hacernos olvidar que el asunto que nuestro romance plantea es un asunto real o, mejor dicho, vulgar. Así que salgamos un momento del ámbito poético y hagamos una breve incursión en la realidad.

El conflicto planteado por el embarazo de la novia debe de ser relativamente reciente. En épocas anteriores, en la Edad Media, por ejemplo, e incluso en los Siglos de Oro, no tenemos noticia (el fenómeno que aquí comentamos es muy diferente del de la seducción donjuanesca) de que algo así se planteara como conflicto social. Y ello seguramente por razones fácilmente comprensibles. Entonces, el paso de la niñez a la vida adulta era muy rápido y se pasaba pronto, tanto en el caso de las mujeres como en el de los hombres, de la infancia al matrimonio. Los progresos de la medicina y de la salubridad han hecho que la vida humana sea hoy considerablemente más larga. La esperanza de vida del hombre europeo actual no guarda parangón con la de hace dos o tres siglos. Lo que se ha alargado no es sólo el cómputo global, sino las edades relativas del hombre: infancia, adolescencia, juventud, madurez, vejez. Pero, además, la aplicación del progreso tecnológico en la esfera productiva ha comportado el que ya no sólo no sea necesario el trabajo de los niños, sino ni siquiera el de los adolescentes y los jóvenes, que cada vez se incorporan más tarde al mercado laboral, convirtiendo la enseñanza obligatoria, como algún autor ha denunciado, en un aparcamiento de menores. Es precisamente el alargamiento de la fase previa a la incorporación al mundo adulto lo que propicia crecientemente la aparición de embarazos en las jóvenes. No podemos considerar aquí la compleja y variada casuística con que este fenómeno se manifiesta. Pero enumeremos, por lo menos, algunos casos posibles:

a) La joven abandona la custodia de su virginidad ante la promesa de matrimonio. Luego esta promesa se cumplirá o no. En este último término tendríamos un conflicto familiar agudo, que en muchos casos condujo a la expulsión de la joven - $\mathrm{y}$ de su hijo- del ámbito familiar y a su entrega al mundo de la prostitución. El romancero de cordel se ha cebado en este último caso, con la truculencia melodramática propia del género:

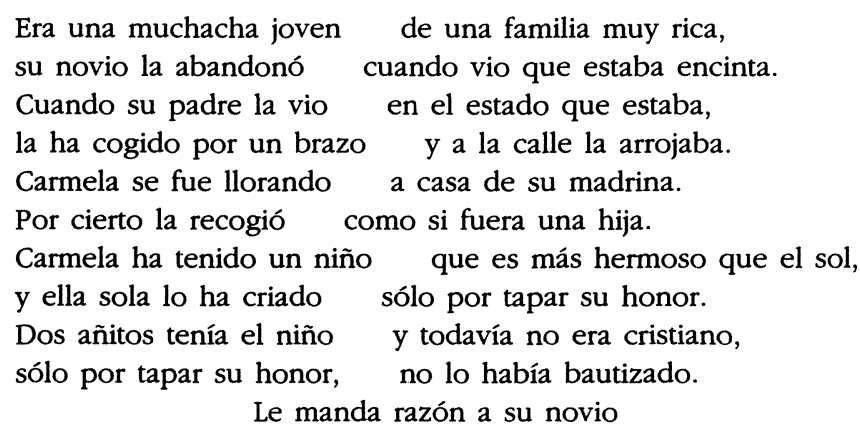




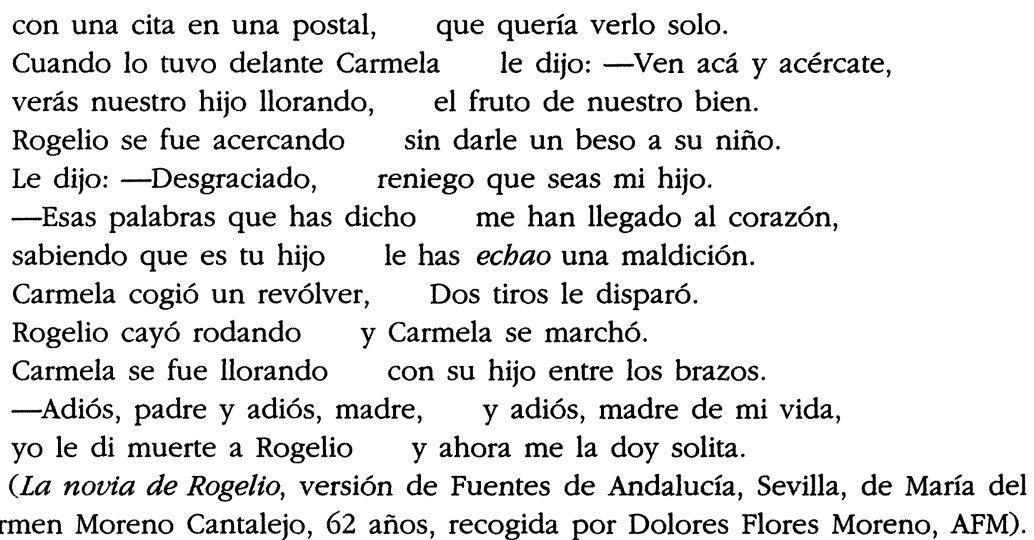

b) La joven busca conscientemente quedar embarazada como medio para escapar de la tutela familiar y alcanzar así, mediante el subsiguiente matrimonio, la autonomía individual y la incorporación al mundo de los adultos.

Es bastante probable que en ambos casos la disponibilidad de medios anticonceptivos resulte indiferente. El embarazo eventual, no querido por la joven, técnicamente posible, resulta extraño. Si una joven mantiene relaciones sexuales sin adoptar ninguna precaución anticonceptiva es porque sabe a lo que se arriesga y asume las consecuencias o cree que las asumirá en su momento.

Desde la perspectiva actual, es decir, desde el horizonte de una sociedad mucho más permisiva y tolerante, y con un alto nivel de polimorfismo familiar, este tipo de conflictos puede parecernos algo ridículo y anacrónico. Y, efectivamente, estos conflictos son anacrónicos... para nosotros. Basta echar la vista unas décadas atrás, sobre todo en un país atrasado y católico como España, para darse cuenta de que, en su momento, estas situaciones no tendrían nada de ridículas o intrascendentes. Puede que algunos necesiten echar mano de los libros de historia, pero a los que tenemos ya cierta edad como para haber alcanzado a vivir los últimos coletazos de la España subdesarrollada nos basta con recurrir a la memoria personal para recordar algunos casos que, efectivamente, hoy nos parecerían ridículos.

Aunque no conozco informes oficiales o estudios sociológicos en relación a este tema, la consulta a varios trabajadores sociales de ayuntamientos de la provincia de Sevilla me sitúa en condiciones de afirmar que el embarazo precoz de chicas que por lo general, aún cursan estudios, es hoy todavía bastante frecuente, a pesar de las campañas de información o de la facilidad -impensable en otros tiempos- para conseguir medios 
anticonceptivos del tipo que sea. La respuesta familiar varía según las clases sociales. En la clase media, suelen ser los propios padres de la joven los que se oponen a la continuidad del embarazo, y convencen a la chica para que lo interrumpa, generalmente en una clínica privada y con toda discreción. Otra cosa, piensan los padres, sería hipotecar el futuro de su hija, bien en el plano familiar, bien en el plano profesional. Por el contrario, en las clases populares, lo más corriente es que sean los padres los que deseen que el matrimonio se produzca antes de que nazca el niño. Se puede pensar que las clases populares perpetúan una moral que las clases más ilustradas ya han abandonado, pero también que la joven de clase humilde no piensa en seguir una carrera que no sea la del matrimonio.

Pero volvamos al romance de los peregrinos. Si lo comparamos con el romance de cordel de La novia de Rogelio, arriba transcrito, comprobaremos que la diferencia no estriba sólo en amor gozoso (Los primos...) frente a amor desgraciado (La novia...), sino en que el romance tradicional (por muy reciente que sea) prescinde de detalles ociosos y resulta más sugerente y universal, y por ello más poético, que el muy circunstanciado romance de ciego de La novia de Rogelio. Así pues, en el romance de los peregrinos asistimos al triunfo del amor, a la gozosa restauración del orden (en uno nuevo donde la transgresión queda asumida), a la reincorporación incluso de aquellos que eventualmente lo subvierten o lo violan. La resolución del romance puede presentarse de muchas formas, pero su sentido es siempre el mismo. Puede ser que el Papa mande una leve penitencia tras su absolución ${ }^{21}$. Puede que el peregrino salga huyendo con su peregrina al comprobar la lasciva conducta del Papa (y es entonces el público y la naturaleza de las cosas lo que los absuelve). Puede que el Papa se niegue a otorgar su perdón, y entonces es el público el que interviene rogando su clemencia o que sean los propios peregrinos los que apelen a una instancia superior y definitiva: "Si no me salva Usía me salva el cielo", "Si usted no nos perdona, nos perdona Dios". En todos los casos el sentido del romance es el mismo.

${ }^{21}$ En una versión de Antequera (Málaga), leemos (habla el Papa): "-Dile a tu madre que haga la cama/ que la pelegrinita ya está casada", lo que constituye una sanción canónica del hecho, y su reabsorción y asimilación. En definitiva, la autoridad asume la transgresión de los jóvenes y los reintegra al sistema. Ver Francisco LÓPEZ ESTRADA, "El romance de Don Bueso y la canción de La peregrinita en el cancionero folkórico de Antequera", en José M. ${ }^{2}$ LÓPEZ DE ABIADA y Augusta LÓPEZ BERNASOCCHI, De los romances-villancico a la poesia de Claudio Rodríguez. 22 ensayos sobre literaturas española e hispanoamericana en bomenaje a Gustav Siebenmann (Madrid: José Esteban Editor, 1984), p. 258. 
Retomemos ahora el hilo teórico con el que comenzábamos a tejer este trabajo. El cantor de romances es un lector, un intérprete, no un autor. $\mathrm{Ni}$ los diversos episodios de la intriga, ni las variantes léxicas o geográficas alteran el sentido de la fábula. Interpretado de diversas formas, el romance es y sigue siendo fiel a sí mismo. Su lección será más clara o más oscura, se cargarán las tintas en unos aspectos o en otros, pero el sentido del romance no varía. No existe el autor-legión, sino el lector legión, o mejor dicho, la legión de lectores, de cantores, de intérpretes, que transparentan o explicitan su lectura a través de las versiones que guardan en su memoria y exteriorizan en su voz.

El verdadero autor de este romance tal vez no lo conozcamos nunca. Lo que sí sabemos es que ninguna de las versiones conocidas es anterior al siglo XX. No sólo su forma métrica de seguidillas es moderna, también lo es su asunto. Parece, pues, que el romancero, aún en el siglo $\mathrm{xx}, \mathrm{o}$ muy poco antes, ha vuelto a dar forma poética a la resolución de un conflicto vulgar. Ha vuelto a ser útil y divertido. La etapa aédica o creativa ${ }^{22}$ no terminó del todo con el siglo xvi. No estamos, pues, ante una literatura muerta, sino ante una literatura vigente. Por lo menos hasta hoy.

\author{
ENRIQUE BALTANÁS \\ Fundación Machado \\ Sevilla
}

Aunque a simple vista el romance de Los primos romeros pueda entenderse desde una perspectiva surrealista, anticlerical o incestuosa, aquí se propone una lectura coherente con la mayoría de los textos romancísticos orales modernos: un conflicto tan familiar y vulgar como la "boda de penalty", visto desde una perspectiva poética e incluso indulgente. Al mismo tiempo, y a propósito de este romance, se dilucidan algunas cuestiones teóricas como el papel del transmisor (¿autor o lector?) y la propia naturaleza del texto oral.

Although superficially the romance of Los primos romeros could be interpreted since a surrealist, anticlerical and incestuous perspective, here it is offered a lecture coherent with most of the romancistic oral texts: a conflict so familiar and vulgar as the "wedding by penalty", viewed since a poetic and inclosed indulgent perspective. For the purpose of this romance, theoretical questions as the role of the transmitter (¿author or reader?) and the nature of oral texts are examined at once.

22 Cfr. Ramón MENÉndez Pidal, op. cit., t. II, p. 17 y ss. 